\title{
The Venus Strategic Plan
}

A White Paper for the Planetary Decadal Survey 2023-2032

Noam R. Izenberg, (noam.izenberg@jhuapl.edu, 443-778-7918, Johns Hopkins University Applied Physics Laboratory (JHUAPL), Laurel, Maryland, USA)

M. Darby Dyar (mdyar@psi.edu, Planetary Science Institute, Tucson, AZ, USA)

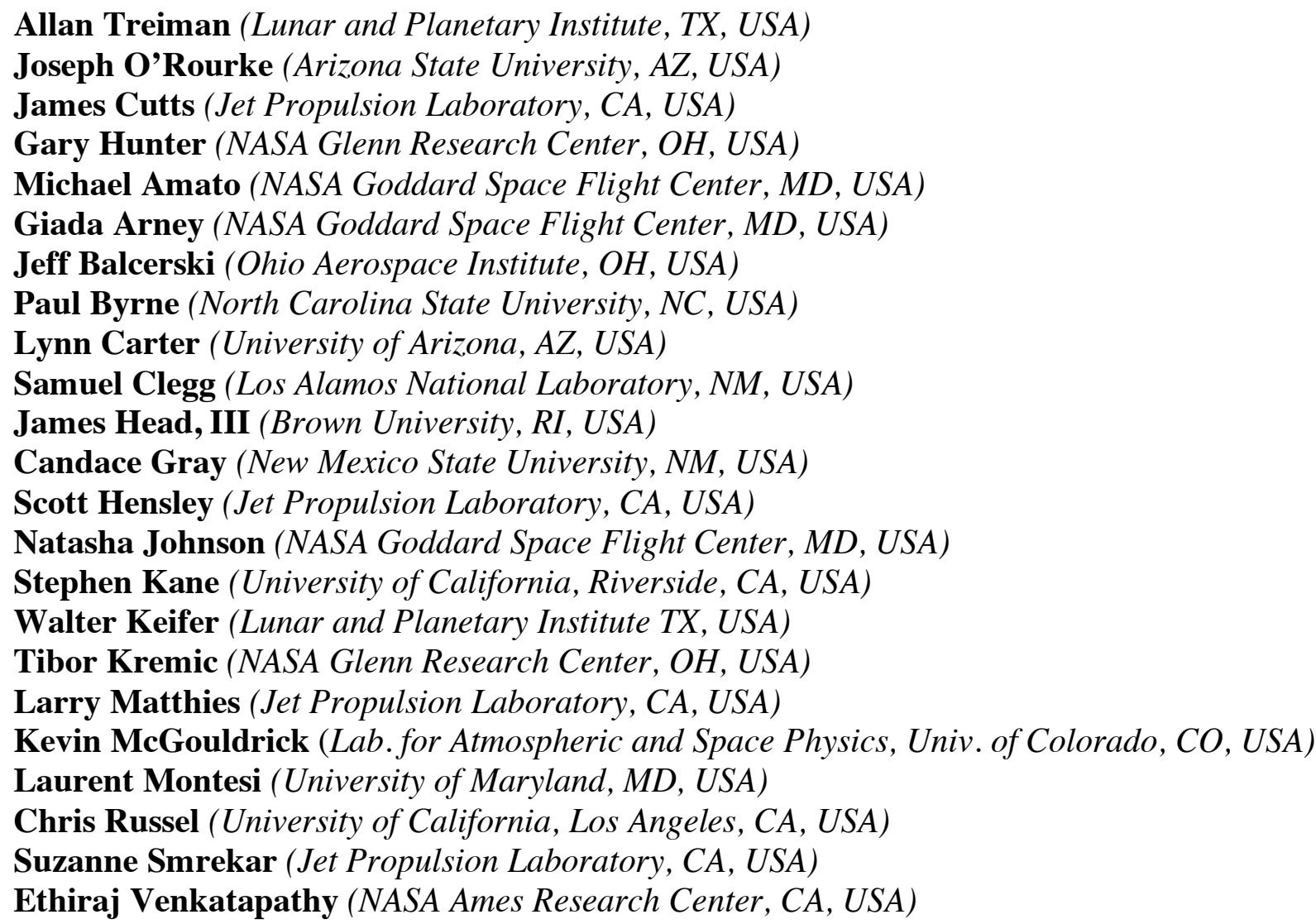




\section{The Venus Strategic Plan}

\section{Key Points: We summarize the 2019 revision of the Venus Strategic Documents, with science priorities, roadmap, and technology needs identified for Decadal Survey consideration.}

\section{Introduction}

Why Venus and why now? Venus plays a pivotal role in our understanding of the origin, evolution, and habitability of rocky planets in our solar system and throughout the galaxy. Venus has key characteristics of habitable planets: geologic activity, a substantial secondary atmosphere, past surface water, and possibly a past dynamo. Of all the numerous Earth-sized exoplanets thus far discovered, none is more similar to Earth and more accessible to us than Venus. Venus acts as a proxy for those exoplanets. NASA has visited all other major rocky bodies of the solar system in the last two decades, including several missions to both the Moon and Mars.

The Venus Exploration Analysis Group (VEXAG) is NASA's community-based forum designed to provide scientific input and technology development plans for planning and prioritizing Venus exploration over the next several decades. VEXAG is chartered by NASA's Planetary Science Division (PSD) in the Science Mission Directorate (SMD) and reports its findings to NASA. Open to all interested scientists, VEXAG regularly evaluates Venus exploration goals, scientific objectives, investigations, and critical measurement requirements, including recommendations for the NRC Decadal Survey and the Solar System Exploration Strategic Roadmap. This document summarizes the three planning documents completed in 2019 as the culmination of year-long process with frequent community outreach and input [1-3].

The VEXAG Goals, Objectives, and Investigations (GOI) document [1] is a community consensus document that describes the scientific discoveries needed to fill the enormous gaps in comparative planetology that will advance our understanding of planet evolution and habitability.

A suite of missions is ready and actively being proposed to fill these gaps. The breadth of highly-rated mission proposals to NASA's Discovery and New Frontiers programs reflects the compelling nature of Venus and the science drive to understand its evolution from interior to surface to atmosphere. The high ratings, supported by funded Phase A studies of recent Venus mission proposals, demonstrate both technical feasibility and the value of Venus science in the coming decade. The U.S. is poised and primed with the advanced technologies, solid mission concepts, and talented, enthusiastic workforce necessary to resume international leadership of a Venus exploration program. The VEXAG Roadmap for Venus Exploration [2] delineates how we can return to our nearest neighbor.

The missions in the Roadmap are enabled by the technologies described in the VEXAG Venus Technology Plan [3], which performs a detailed assessment of the maturity of the technologies needed to conduct missions to Venus. It expands upon a series of earlier studies of small satellites [4], aerial platforms [5], and "Venus Bridge" small mission approaches to Venus exploration [6]. While many of scientifically important missions to Venus can be implemented with existing technology, some fundamental science questions can only be successfully answered with new mission paradigms.

Collectively, these three Venus Strategic Documents lay out the vision of the Venus Exploration Analysis Group (VEXAG) and the Venus community it represents. 


\section{Venus Goals, Objectives, and Investigations.}

Through an extended process including input from the science community at three town hall meetings and a workshop at LPSC in 2019, the VEXAG community has developed a comprehensive list of Scientific Goals, Objectives, and Investigations. They are intended to address the priorities of previous the decadal surveys and motivate and advise future efforts. In particular, NASA's future exploration of Venus should strive toward three non-prioritized Goals:

Goal \#1. Understand Venus' early evolution and potential habitability to constrain the evolution of Venus-sized (exo)planets,

Goal \#2. Understand atmospheric composition and dynamics on Venus, and

Goal \#3. Understand the geologic history preserved on the surface of Venus and the present-day couplings between the surface and atmosphere.

The GOI document [1] and Table 1 here detail the six Objectives and 23 Investigations that support these goals. Every Investigation was judged to be technically and programmatically feasible and scientifically valuable. Collectively, they support a sustained program of exploration would unveil Venus' workings with broad scientific implications for our Solar System and beyond.

Table 1 summarizes this entire report. Because understanding Venus as a planetary system requires progress in many scientific areas, Goals and Objectives are not prioritized. Investigations are typed as Essential (1), Important (2), or Targeted (3) based on their relationship to the corresponding Objective. Completion of all Essential Investigations fundamentally addresses their Objective. Important Investigations address many aspects of their Objective and provide valuable context for other Investigations. Targeted Investigations address particular aspects of an Objective that significantly contribute to our overall understanding of Venus. Investigations with the same ranking have the same level of priority. All listed Investigations are deemed to be significant and worthy of programmatic consideration.

\section{The Roadmap for Venus Exploration}

Exploration of Venus provides both major technical challenges and extraordinary scientific opportunities. This Roadmap for Venus Exploration [2] lays out a framework for pursuing encompassing observations of the atmosphere, surface, and interior using a variety of mission modes ranging from orbiters, aerial platforms, long-duration landers, and probes, and opportunistic leveraging of events such as flybys of non-Venus missions. It was developed for the space science community by the Venus Exploration Analysis Group (VEXAG) to provide guidance to the Planetary Science Division and the Planetary Science Decadal Survey process. Scientific guidance for the roadmap is provided by the GOI [1], and the Venus Technology Plan [3], details the technological advances enabling multiple new mission modes.

Summarized Roadmap. The current planetary mission programmatic framework is dominated by competitive missions in the Discovery and New Frontiers programs. The Venus Roadmap lays out credible mission options to guide planning and technology investments and to address some of the consequences of different choices. The detailed document [2] considers how Roadmap missions (Figures 1, 2, Table 2) fit with the existing NASA opportunities, NASA Flagship missions, and international collaborations. 
Table 1. VEXAG Goals, Objectives, and Investigations

\begin{tabular}{|c|c|c|}
\hline Goal & Objective & Investigation \\
\hline \multirow{8}{*}{$\begin{array}{l}\text { I. Understand } \\
\text { Venus' early } \\
\text { evolution and } \\
\text { potential } \\
\text { habitability to } \\
\text { constrain the } \\
\text { evolution of } \\
\text { Venus-size } \\
\text { (exo)planets. }\end{array}$} & \multirow{4}{*}{$\begin{array}{c}\text { A. Did Venus } \\
\text { have temperate } \\
\text { surface conditions } \\
\text { and liquid water at } \\
\text { early times? }\end{array}$} & $\begin{array}{l}\text { HO. Hydrous Origins (1). Determine whether Venus shows evidence for } \\
\text { abundant silicic igneous rocks and/or ancient sedimentary rocks. }\end{array}$ \\
\hline & & $\begin{array}{l}\text { RE. Recycling (1). Search for structural, geomorphic, and chemical } \\
\text { evidence of crustal recycling on Venus. }\end{array}$ \\
\hline & & $\begin{array}{l}\text { AL. Atmospheric Losses (2). Quantify the processes by which the } \\
\text { atmosphere of Venus loses mass to space, including interactions between } \\
\text { magnetic fields and incident ions and electrons. }\end{array}$ \\
\hline & & $\begin{array}{l}\text { MA. Magnetism (3). Characterize the distribution of any remanent } \\
\text { magnetism in the crust of Venus. }\end{array}$ \\
\hline & \multirow{4}{*}{$\begin{array}{c}\text { B. How does } \\
\text { Venus elucidate } \\
\text { possible pathways } \\
\text { for planetary } \\
\text { evolution in } \\
\text { general? }\end{array}$} & $\begin{array}{l}\text { IS. Isotopes (1). Measure the isotopic ratios and abundances of } \mathrm{D} / \mathrm{H} \text {, noble } \\
\text { gases, oxygen, nitrogen, and other elements in the atmosphere of Venus. }\end{array}$ \\
\hline & & $\begin{array}{l}\text { LI. Lithosphere (1). Determine lithospheric parameters on Venus that are } \\
\text { critical to rheology and potential geodynamic transitions, including: stress } \\
\text { state, water content, physical structure, and elastic and mechanical } \\
\text { thicknesses. }\end{array}$ \\
\hline & & $\begin{array}{l}\text { HF. Heat flow (2). Determine the thermal structure of the lithosphere of } \\
\text { Venus at present day and measure in situ heat flow. }\end{array}$ \\
\hline & & $\begin{array}{l}\text { CO. Core (2). Measure the size of the core of Venus and determine whether } \\
\text { it remains partially liquid. }\end{array}$ \\
\hline Goal & Objective & Investigation \\
\hline \multirow{8}{*}{$\begin{array}{l}\text { II. Understand } \\
\text { atmospheric } \\
\text { dynamics and } \\
\text { composition on } \\
\text { Venus. }\end{array}$} & \multirow{3}{*}{$\begin{array}{l}\text { A. What processes } \\
\text { drive the global } \\
\text { atmospheric } \\
\text { dynamics of } \\
\text { Venus? }\end{array}$} & $\begin{array}{l}\text { DD. Deep Dynamics (1). Characterize the dynamics of the lower } \\
\text { atmosphere (below about } 75 \mathrm{~km} \text { ) of Venus, including: retrograde zonal } \\
\text { super-rotation, meridional circulation, radiative balances, mountain waves, } \\
\text { and transfer of angular momentum. }\end{array}$ \\
\hline & & $\begin{array}{l}\text { UD. Upper Dynamics (1). In the upper atmosphere and thermosphere of } \\
\text { Venus, characterize global dynamics and interactions between space } \\
\text { weather and the ionosphere and magnetosphere. }\end{array}$ \\
\hline & & $\begin{array}{l}\text { MP. Mesoscale Processes (2). Determine the role of mesoscale dynamics } \\
\text { in redistributing energy and momentum throughout the atmosphere of } \\
\text { Venus. }\end{array}$ \\
\hline & \multirow{5}{*}{$\begin{array}{l}\text { B. What processes } \\
\text { determine the } \\
\text { baseline and } \\
\text { variations in Venus } \\
\text { atmospheric } \\
\text { composition and } \\
\text { global and local } \\
\text { radiative balance? }\end{array}$} & $\begin{array}{l}\text { RB. Radiative Balance (1). Characterize atmospheric radiative balance and } \\
\text { how radiative transport drives atmospheric dynamics on Venus. }\end{array}$ \\
\hline & & $\begin{array}{l}\text { IN. Interactions (1). Characterize the nature of the physical, chemical, and } \\
\text { possible biological interactions among the constituents of the Venus } \\
\text { atmosphere. }\end{array}$ \\
\hline & & $\begin{array}{l}\text { AE. Aerosols (2). Determine the physical characteristics and chemical } \\
\text { compositions of aerosols in Venus atmosphere as they vary with elevation, } \\
\text { including discrimination of aerosol types/components. }\end{array}$ \\
\hline & & $\begin{array}{l}\text { UA. Unknown Absorber (2). Characterize the unknown short-wavelength } \\
\text { absorber in the upper atmosphere of Venus and its influence on local and } \\
\text { global processes. }\end{array}$ \\
\hline & & $\begin{array}{l}\text { OG. Outgassing (3). Determine the products of volcanic outgassing on } \\
\text { Venus and their effects on atmospheric composition. }\end{array}$ \\
\hline
\end{tabular}


Table 1 (continued). VEXAG Goals, Objectives, and Investigations

\begin{tabular}{|c|c|c|}
\hline Goal & Objective & Investigation \\
\hline \multirow{7}{*}{$\begin{array}{l}\text { III. Understand } \\
\text { the geologic } \\
\text { history preserved } \\
\text { on the surface of } \\
\text { Venus and the } \\
\text { present-day } \\
\text { couplings } \\
\text { between the } \\
\text { surface and } \\
\text { atmosphere. }\end{array}$} & \multirow{4}{*}{$\begin{array}{l}\text { A. What geologic } \\
\text { processes have } \\
\text { shaped the surface } \\
\text { of Venus? }\end{array}$} & $\begin{array}{l}\text { GH. Geologic History (1). Develop a geologic history for Venus by } \\
\text { characterizing the stratigraphy, modification state, and relative ages of } \\
\text { surface units. }\end{array}$ \\
\hline & & $\begin{array}{l}\text { GC. Geochemistry (1). Determine elemental chemistry, mineralogy, and } \\
\text { rock types at localities representative of global geologic units on Venus. }\end{array}$ \\
\hline & & $\begin{array}{l}\text { GA. Geologic Activity (1). Characterize current volcanic, tectonic, and } \\
\text { sedimentary activity that modifies geologic units and impact craters and } \\
\text { ejecta on Venus. }\end{array}$ \\
\hline & & $\begin{array}{l}\text { CR. Crust (2). Determine the structure of the crust of Venus in three } \\
\text { dimensions and thickness across the surface. }\end{array}$ \\
\hline & \multirow{3}{*}{$\begin{array}{l}\text { B. How do the } \\
\text { atmosphere and } \\
\text { surface of Venus } \\
\text { interact? }\end{array}$} & $\begin{array}{l}\text { LW. Local Weathering (1). Evaluate the mineralogy, oxidation state, and } \\
\text { changes in chemistry of surface-weathered rock exteriors at localities } \\
\text { representative of global geologic units on Venus. }\end{array}$ \\
\hline & & $\begin{array}{l}\text { GW. Global Weathering (2). Determine the causes and spatial extents of } \\
\text { global weathering regimes on Venus. }\end{array}$ \\
\hline & & $\begin{array}{l}\text { CI. Chemical Interactions (3). Characterize atmospheric composition and } \\
\text { chemical gradients from the surface to the cloud base both at key locations } \\
\text { and globally. }\end{array}$ \\
\hline
\end{tabular}

Near-term Proposal Opportunities - 2020 to 2022. Before the next Planetary Science Decadal Survey makes its recommendations, we anticipate that two Discovery calls (one ongoing at this writing), one New Frontiers opportunity, and smaller ride-along or other missions of opportunity may be solicited. The Decadal committee will be convening while these missions are being proposed and selected, but roadmap suggestions and priorities are shown in Figure 1.

Mid-term Proposal Opportunities - 2023 to 2032. During this Planetary Decadal Survey period, up to four Discovery opportunities, at least two New Frontiers announcements, and up to two Flagship class new starts are anticipated. The larger class of missions enables more capable platforms, as well as multiple platform missions to be considered.

In addition to the platforms that would be available in the near-term, the following ones can be considered for this 2023-2032 timeframe; Surface Platform-Short-Lived, Surface Platform-Long-lived, Aerial Platform-Variable Altitude - Mid Cloud (Figure. 1).

New Frontiers and Flagship opportunities available in this time period would enable missions involving multiple exploration platforms. Deploying several platforms on a single launch rather than sequentially in separate launches could provide both operational and scientific synergy if deployed simultaneously at Venus. Three example concepts were chosen for presentation here based on the following criteria, but this is not an exclusive list: Mission science should represent a substantial gain over that feasible with a single Discovery mission; Missions must be technically ready in the time-frame of the next Planetary Science Decadal Survey (2022 - 2032); Missions could be more costly than Discovery $(>\$ 500 \mathrm{M}$ in 2020 dollars), include the New Frontiers category $\$ 1 \mathrm{~B}$, and extend to Flagship approximately $\$ 2 \mathrm{~B}+$. 


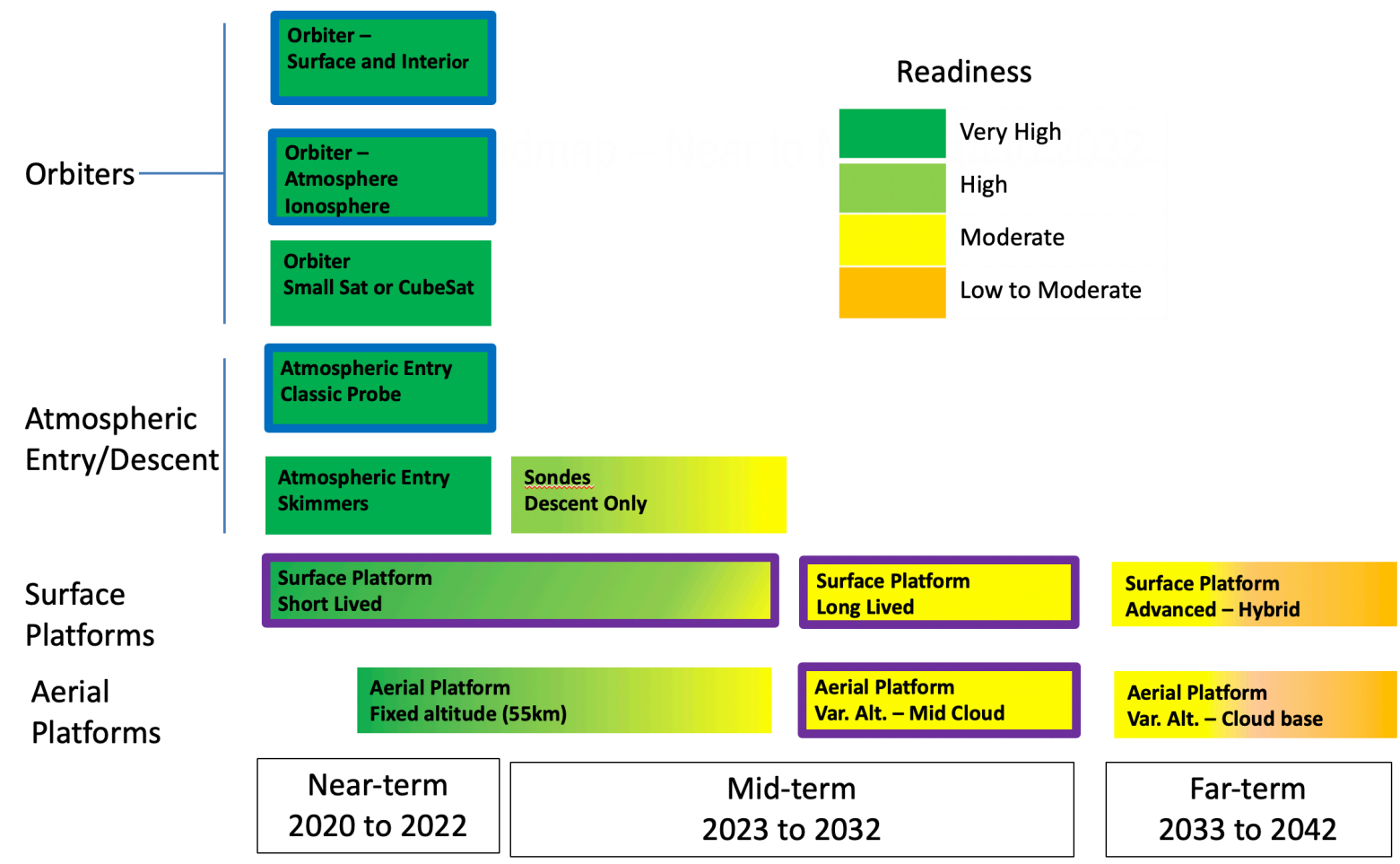

Figure 1. Time frames in which exploration platforms could be ready for deployment are ordered in based on their readiness. Readiness is a composite measure based on technology maturity, complexity and resource needs. Near-term Roadmap missions have very high and high readiness. Mid-term Roadmap missions have high and moderate readiness. Far-term Roadmap missions have moderate and low readiness.

The three aspirational multi-platform concepts here resemble concepts previously studied by or proposed to NASA. However, there are significant differences reflecting recent scientific and technological advances (Figure 2).

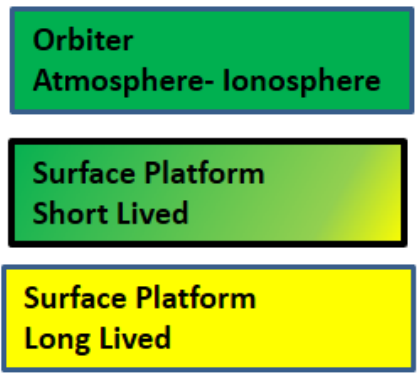

Multi Platform Mission Option A

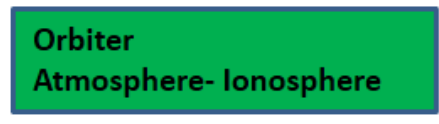

\section{Atmospheric Entry Classic Probe}

\section{Aerial Platform Var. Alt. - Mid Cloud}

Multi Platform Mission Option B

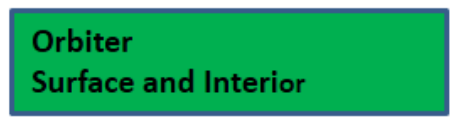

\section{Atmospheric Entry} Classic Probe

Surface Platform Long Lived

Multi Platform Mission Option C

Figure 2. Options for Multi-Platform Missions for the Decadal Survey Period (2023 to 2032). Each mission includes three exploration platforms delivered to Venus with a single spacecraft. The in-situ platforms (landers, probes and aerial platform) would be delivered into the atmosphere in a single aero shell. Color indicates current technical readiness (See Figure 1). 
The ability to integrate multiple platforms in a single mission provides a number of scientific and technical advantages that are summarized in Table 2 and detailed in [2].

Table 2. Comparisons of Multi Mission Platform candidates and their scientific and engineering synergies

\begin{tabular}{|c|c|c|c|c|}
\hline \multicolumn{2}{|c|}{ Roadmap Mission Two } & \multirow{2}{*}{$\begin{array}{l}\text { Scientific } \\
\text { Complementary } \\
\text { and Synergy } \\
\end{array}$} & \multirow[b]{2}{*}{ Mission Synergy } & \multirow{2}{*}{$\begin{array}{l}\text { Mission Synergy } \\
\text { Guidance \& } \\
\text { Localization } \\
\end{array}$} \\
\hline Designation & Platforms Included & & & \\
\hline MPM-A & $\begin{array}{l}\text { Surface Platform - Short } \\
\text { lived } \\
\text { Surface Platform - Long } \\
\text { lived } \\
\text { Orbiter Atmosphere - } \\
\text { Ionosphere }\end{array}$ & $\begin{array}{l}\text { Compare diurnal } \\
\text { measurements of } \\
\text { surface } \\
\text { temperature with } \\
\text { orbital } \\
\text { remote sensing }\end{array}$ & $\begin{array}{l}\text { Orbital relay is } \\
\text { essential for } \\
\text { recovering data } \\
\text { from long lived } \\
\text { surface platforms }\end{array}$ & $\begin{array}{l}\text { Enable refinement of } \\
\text { entry and descent } \\
\text { trajectory for the } \\
\text { surface platforms }\end{array}$ \\
\hline MPM-B & $\begin{array}{l}\text { Aerial Platform - Variable } \\
\text { Altitude } \\
\text { Descent Probe } \\
\text { Orbiter Atmosphere \& } \\
\text { Ionosphere }\end{array}$ & $\begin{array}{l}\text { Compare orbital } \\
\text { spectral signatures } \\
\text { and cloud tracking } \\
\text { with in situ } \\
\text { observations }\end{array}$ & $\begin{array}{l}\text { Orbital relay } \\
\text { increases data } \\
\text { return by } 100 \times \\
\text { from the aerial } \\
\text { platform relative to } \\
\text { direct to Earth } \\
\end{array}$ & $\begin{array}{l}\text { Enables accurate } \\
\text { localization of the } \\
\text { position and velocity } \\
\text { of the aerial platform } \\
\text { as it is propelled by } \\
\text { the RZS }\end{array}$ \\
\hline MPM-C & $\begin{array}{l}\text { Descent Probe } \\
\text { Orbiter - Surface and } \\
\text { Interior } \\
\text { Surface Platform- Long } \\
\text { lived }\end{array}$ & $\begin{array}{l}\text { Radar imaging from } \\
\text { orbit provides } \\
\text { context for high } \\
\text { resolution visual } \\
\text { images from } \\
\text { descent probe }\end{array}$ & $\begin{array}{l}\text { May supplement } \\
\text { data returned from } \\
\text { the cruise stage } \\
\text { deploying probe }\end{array}$ & $\begin{array}{l}\text { May enable precise } \\
\text { determination of } \\
\text { point of entry and } \\
\text { descent trajectory }\end{array}$ \\
\hline
\end{tabular}

\section{The Venus technology Plan}

This Technology Plan [3] is simultaneously a status report, a development plan, and guiding document for the accompanying GOI [1] and Roadmap [2] documents. The plan builds progressively from low to very high levels of maturity that could be accomplished over time with technology investments. Sections encompass both what is necessary for a single complete mission profile, and the broad array of technologies and components needed for wide range of mission proposals today and in the future. Needs for NASA investment arising from this study are summarized in Table 3.

While many of scientifically important missions to the second planet can be implemented with existing technology, some fundamental science questions can only be successfully answered with new mission paradigms. Some ambitious missions require investment in and maturation of new technologies, while other new technologies can leverage recent advances and commercial developments. An effective Venus exploration technology program includes a balance of investments in short-term missions and technology, enabling new paradigms and more ambitious future missions in the medium- and long-term. This Venus Technology Plan performs a detailed assessment of the maturity of the technologies needed to conduct missions to Venus. 
Table 3. Major Needs Arising from This Study

\begin{tabular}{|c|c|}
\hline Area & Needs \\
\hline Entry Technology & Funding to ensure the entry technology capability does not atrophy \\
\hline Subsystems & $\begin{array}{l}\text { Development of high temperature electronics, sensors, and high-density power sources } \\
\text { for the Venus environment with increasing capability }\end{array}$ \\
\hline Aerial Platforms & $\begin{array}{l}\text { A competitive program to determine which Variable Altitude balloons approach is most } \\
\text { viable }\end{array}$ \\
\hline In situ Instruments & $\begin{array}{l}\text { Adaptation of flight-demonstrated technology and development of new instrument } \\
\text { systems uniquely designed for the Venus environment }\end{array}$ \\
\hline $\begin{array}{l}\text { Communications and } \\
\text { Infrastructure }\end{array}$ & $\begin{array}{l}\text { Study of the feasibility of and methods for establishing a Venus communications and } \\
\text { navigation infrastructure }\end{array}$ \\
\hline Advanced Cooling & Investments in highly efficient mechanical thermal conversion and cooling devices \\
\hline Descent and Landing & $\begin{array}{l}\text { New concepts for adapting precision descent and landing hazard avoidance } \\
\text { technologies to operate in Venus' dense atmosphere }\end{array}$ \\
\hline Autonomy & $\begin{array}{l}\text { Transitioning of automation and autonomous technologies to Venus-specific } \\
\text { applications }\end{array}$ \\
\hline Small platforms & $\begin{array}{l}\text { Development of small platform as additions to larger missions, as well as a new mission } \\
\text { type designed around small platforms }\end{array}$ \\
\hline $\begin{array}{l}\text { Facilities and } \\
\text { Infrastructure }\end{array}$ & $\begin{array}{l}\text { Support of laboratory facilities and capabilities for instrument and flight systems, } \\
\text { including critical technologies to avoid atrophy of capabilities }\end{array}$ \\
\hline $\begin{array}{l}\text { Modeling and } \\
\text { Simulations }\end{array}$ & Establishment of a system science approach to Venus modeling \\
\hline $\begin{array}{l}\text { Unique Venus } \\
\text { Technology }\end{array}$ & $\begin{array}{l}\text { Continued and expanded support for programs such as HOTTech, and other technology } \\
\text { development }\end{array}$ \\
\hline
\end{tabular}

\section{References}

[1] VEXAG GOI Focus Group. (2019a). Venus Goals, Objectives, and Investigations, https://www.lpi.usra.edu/vexag/reports/VEXAG_Venus_GOI_Current.pdf

[2] VEXAG Roadmap Focus Group. (2019b). Roadmap for Venus Exploration, https://www.lpi.usra.edu/vexag/reports/VEXAG_Venus_Roadmap_Current.pdf

[3] VEXAG Technology Focus Group. (2019c). Venus Technology Plan, https://www.lpi.usra.edu/vexag/reports/VEXAG_Venus_Techplan_Current.pdf

[4] NASA (2017) Planetary Science Deep Space SmallSat Studies (PSDS3) program, https://www.nasa.gov/feature/nasa-selects-cubesat-smallsat-mission-concept-studies.

[5] Venus Aerial Platform Study Team. (2018). Scientific Exploration of Venus with Aerial Platforms.

https://www.lpi.usra.edu/vexag/reports/Venus_Aerial_Platforms_Final_Report_Summary _Report_10_25_2018.pdf

[6] VEXAG Venus Bridge Group. 2018. Venus Bridge: Examining a Low-Cost Renewal of American Exploration of Earth's Divergent Sibling. https://www.lpi.usra.edu/vexag/reports/Venus_Bridge_Summary_Report.pdf 